\title{
A redescription of Haemogregarina fitzsimonsi Dias, 1953 and some comments on Haemogregarina parvula Dias, 1953 (Adeleorina: Haemogregarinidae) from southern African tortoises (Cryptodira: Testudinidae), with new host data and distribution records
}

\author{
Courtney A. Cook ${ }^{1}$, Nico J. Smit ${ }^{1}$ and Angela J. Davies ${ }^{1,2}$ \\ ${ }^{1}$ Department of Zoology, University of Johannesburg, Johannesburg, South Africa; \\ ${ }^{2}$ School of Life Sciences, University of Kingston upon Thames, London, Surrey, UK
}

\begin{abstract}
Blood films were examined from 154 wild and captive tortoises from four provinces of South Africa, including Gauteng, Kwazulu-Natal, North West and Western Cape. The five species of chelonians studied were Chersina angulata (Schweigger), Kinixys belliana belliana (Gray), K. lobatsiana Power, K. natalensis Hewitt, and Stigmochelys pardalis (Bell). Two species of haemogregarines, previously reported from Mozambique, were identified in blood films, namely Haemogregarina fitzsimonsi Dias, 1953 and Haemogregarina parvula Dias, 1953. Additional stages of development (trophozoites and probable meronts, merozoites and immature gamonts) in blood preparations from South Africa warranted the redescription of $H$. fitzsimonsi. A variety of hosts and broad host distribution range were observed for this haemogregarine, with all five species of tortoises parasitized, wild and captive, from all four provinces, in all seasons. In contrast, only two individuals of $K$. b. belliana and one S. pardalis, all three captive in KwazuluNatal, contained H. parvula with encapsulated stages resembling those of Hemolivia mauritanica (Sergent et Sergent, 1904). For $H$. fitzsimonsi, parasite prevalences, but not parasitaemias, were significantly higher in captive than wild S. pardalis; captive female $S$. pardalis also showed a significantly greater prevalence of infection than males, but younger, lighter hosts were not significantly more heavily parasitized than older, heavier individuals. The ticks, Amblyomma marmoreum Koch, 1844 and A. sylvaticum (De Geer, 1778), found attached to some tortoises, may prove to be definitive hosts for the two species of haemogregarines observed.
\end{abstract}

Key words: blood parasites, haemogregarines, Haemogregarina fitzsimonsi, Haemogregarina parvula, tortoises, Chersina angulata, Kinixys spp., Stigmochelys pardalis, Africa

Few records exist of haematozoans infecting African land tortoises (Chelonia, Cryptodira, Testudinidae) and these were published mainly during the early part of the last century (see Lainson and Naiff 1998). Examples of early descriptions were of: Haemogregarina mauritanica Sergent et Sergent, 1904 in Testudo graeca (L.) (syn. Testudo mauritanica) from Algeria (Sergent and Sergent 1904); Haemamoeba testudinis Laveran, 1905 in Stigmochelys pardalis (Bell) (syns. Testudo pardalis, Geochelone pardalis) from southern Africa (Laveran 1905); Plasmodium roumei Bouet, 1909 in Kinixys belliana belliana (Gray) (syns. Testudo belliana, Cinixys belliana) from the Ivory Coast (Bouet 1909); a Haemocystidium sp. from west African tortoises $K$. b. belliana, Kinixys erosa (Schweigger) (syns. Testudo erosa, C. erosa) and Kinixys homeana (Bell) (syn. Cinixys homeana), all housed at the Zoological Gardens in London (Plimmer 1912); and Haemogregarina bruneti Commes, 1919 and a trypanosome in K. homeana from Mali (Commes 1919). Some of these protozoans have since been ascribed to different genera with Haemamoeba and Haemocystidium spp. becoming Haemoproteus spp., and H. mauritanica being transferred to the genus Hemolivia Petit, Landau, Baccam et Lainson, 1990 (see Lainson and Naiff 1998, Široký et al. 2007). The most recent research on blood protozoans from land tortoises in Africa (Dias 1953), reported two species of haemogregarines (Apicomplexa, Adeleorina, Haemogregarinidae) and one haemoproteid (Apicomplexa, Haemospororida, Haemoproteidae) from two individuals of $K$. $b$. belliana (syn. Kinixys belliana zuluensis) from the coastal town of Maputo, Mozambique. For the haemogregarines, Dias (1953) recorded intraerythrocytic gamont-like stages of Haemogregarina fitzsimonsi Dias, 1953 and immature and mature forms of Haemogregarina parvula Dias, 1953 within intraerythrocytic capsules.

In the current study, five species of tortoises were examined, both wild and captive, from four provinces within South Africa, across all seasons. The two haemogregarine 
species of Dias (1953) were observed, together with previously unrecorded stages of $H$. fitzsimonsi, necessitating a redescription of this species. Distribution and host records were expanded for both $H$. fitzsimonsi and $H$. parvula. Prevalences and/or parasitaemias with $H$. fitzsimonsi were compared for captive and wild $S$. pardalis, female and male tortoises, and for younger and older animals. Tortoise ectoparasites that might serve as definitive hosts for the two haemogregarine species were identified and finally, doubts were cast on the current classification of the two apicomplexans as members of the genus Haemogregarina (sensu stricto) Danilewsky, 1885.

\section{MATERIALS AND METHODS}

Sample collection. Tortoises $(n=154)$ of five species, the angulate tortoise Chersina angulata (Schweigger), Bell's hinged tortoise Kinixys belliana belliana, the Lobatse hinged tortoise $K$. lobatsiana Power, the Natal hinged tortoise $K$. natalensis Hewitt, and the leopard tortoise Stigmochelys pardalis were examined from the following provinces of the Republic of South Africa: Gauteng (G); Kwazulu-Natal (KZN); North West Province (NWP); and Western Cape (WC) (Table 1). These provinces represented a diverse range of habitats, from the savannah of $\mathrm{G}$, tropical/subtropical coastal habitats of $\mathrm{KZN}$, semi-arid conditions of NWP, to the arid-fynbos of WC. Vetter (2002) was used to name authorities for tortoises examined.

Wild tortoises $(n=84)$ were examined from Rustenburg $\left(25^{\circ} 42^{\prime} \mathrm{S}, 27^{\circ} 5^{\prime} \mathrm{E}\right)$ and from rural markets, both in NWP, and at Hondeklip Bay $\left(30^{\circ} 19^{\prime} \mathrm{S}, 17^{\circ} 16^{\prime} \mathrm{E}\right)$ and Velddrif $\left(32^{\circ} 54^{\prime} \mathrm{S}\right.$, $18^{\circ} 46^{\prime} \mathrm{E}$ ) in WC (Fig. 1). Chelonians (except from rural markets) were captured on foot from October to February (the South African spring and summer) of 2006 and 2007, using a hooked stick to displace dense vegetation, and were examined once, in the field. Since wild tortoises tended to hibernate deep in the holes of larger animals from April to September (autumn and winter), field sampling was suspended during this period. Additional wild tortoises held in rural markets, were each examined once during spring, summer, autumn, and winter between March 2006 and December 2007. Long-term captive tortoises $(n=70)$ were sampled at the National Zoological Gardens (NZG), Pretoria $\left(25^{\circ} 44^{\prime} \mathrm{S}, 28^{\circ} 11^{\prime} \mathrm{E}\right)$, in $\mathrm{G}$, and at Crocodile Creek, Crocodile Valley, and Flag Animal Farm, all three at Ballito $\left(29^{\circ} 32^{\prime} \mathrm{S}\right.$, $30^{\circ} 33^{\prime} \mathrm{E}$ ), in KZN (Fig. 1). Captive tortoises were housed in similar small huts with outdoor pens in which they could be caught easily. These individuals, except for those from the NZG (sampled once during spring, November 2007), were each examined twice between June 2006 and November 2007. The exact origins of rural market (classified as wild, above) and captive tortoises were unknown; however, these animals were understood to have been taken locally (for rural markets), or have been surrendered or confiscated by Nature Conservation and placed in regional zoological facilities (captive animals).

Blood $(\sim 0.1-0.5 \mathrm{ml})$ was taken by needle and syringe from veins and arteries of the fore and hind limbs, jugular veins, or the coccygeal vein of the tail of wild and captive tortoises (see McArthur et al. 2004). Effects of seasonality on prevalence of infection, and parasitaemia, were recorded for wild specimens, with these animals being examined only once (see above). Ex-

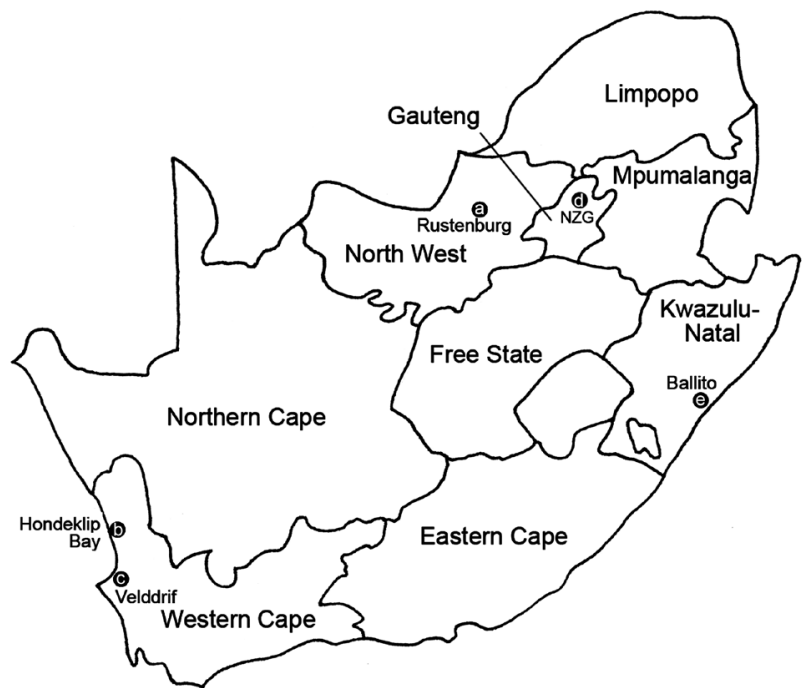

Fig. 1. Locations in South Africa at which tortoises were examined for haematozoans. (a) Rustenburg, including rural markets in NWP, where wild Kinixys lobatsiana and Stigmochelys pardalis were examined. (b) Hondeklip Bay and (c) Velddrif in WC, where wild Chersina angulata were examined. (d) NZG in $\mathrm{G}$, where captive $K$. lobatsiana and $S$. pardalis were examined and (e) Ballito, including Crocodile Creek, Crocodile Valley and Flag Animal Farm, in KZN, where captive C. angulata, Kinixys belliana belliana, K. natalensis and S. pardalis were examined.

cept for those at the NZG, captive tortoises of all five species were marked with nail varnish on their shells following removal of the first blood sample to allow future identification, so that the effects of seasonality and levels of parasitaemia could be assessed over time. Each $S$. pardalis in the NZG's collection was sexed and then weighed $(\mathrm{kg})$ using a set of industrial scales because of the substantial size of some tortoises; these approaches allowed assessment of prevalence and parasitaemia in relation to host gender and size, following blood sampling.

Blood films. Thin blood films from all tortoises were fixed in absolute methanol for $\sim 10$ minutes, Giemsa-stained (FLUKA, Sigma-Aldrich) for 20 minutes, and then screened initially using a $\times 100$ oil immersion objective on an Olympus BX41 light microscope. Subsequently, images of blood parasites were captured using a $\times 100$ oil immersion objective on a Carl Zeiss Axiocam digital camera attached to a Zeiss Axioplan 2 photomicroscope, measurements $(\mu \mathrm{m})$ were taken using AxioVision Release 4.3 (11-2004) software, calibrated to a stage micrometer, and the parasite species infecting the wild and captive host tortoises were recorded (Table 1). Parasitaemias were calculated as infection levels per 100 red blood cells, with $\sim 10^{4}$ erythrocytes examined per blood film.

Ectoparasites. Prior to tortoise release, either to the wild at the site of capture, or back into captivity, ectoparasites that might be definitive hosts for tortoise blood parasites were collected from the chelonians and fixed in $10 \%$ neutral buffered formalin before identification in the laboratory.

When appropriate, the validity of results was tested statistically using Student's $t$-test, and the parasitaemia/weight correlations tested using Conoco for Windows 4.5. 


\section{RESULTS}

\section{General observations on haemogregarines within the blood of tortoises}

Of the South African tortoises $(\mathrm{n}=154$ : 84 wild; 70 captive) screened for blood parasites, 25\% (38/154) overall were parasitized by the two haemogregarine species, H. fitzsimonsi (Table 1, Figs. 2-14) and H. parvula (Table 1, Figs. 15-17). Haemogregarine prevalence varied with host status (wild or captive) and distribution (Table 1). Only captive $C$. angulata lacked haemogregarines and thus, among wild or captive tortoises, H. fitzsimonsi was found in the five species of hosts (C. angulata, K. b. belliana, K. lobatsiana, K. natalensis and S. pardalis) from four provinces (G, KZN, NWP, WC), at prevalences from $5 \%$ to $66 \%$; H. parvula was detected only in captive hosts (K. b. belliana and S. pardalis) from KZN and at prevalences up to $14 \%$. In addition, $H$. fitzsimonsi occurred in wild $C$. angulata, $K$. lobatsiana and $S$. pardalis at parasitaemias between $\sim 1.8 \%$ and $\sim 2.5 \%$, and in captive K. b. belliana, K. lobatsiana, K. natalensis and S. pardalis at levels between $\sim 2.3 \%$ and $\sim 5.1 \%$. Parasitaemias of $H$. parvula in captive $K$. b. belliana and S. pardalis were between $\sim 2.5 \%$ and $\sim 2.6 \%$.

When prevalence of $H$. fitzsimonsi in wild and captive tortoises was examined over the seasons (Table 1), no effect of seasonality was indicated. Younger stages of $H$. fitzsimonsi, that is, trophozoites, probable meronts and merozoites (Figs. 2-5) were found during spring and summer in three captive $S$. pardalis from G, and in two wild $C$. angulata from WC. The tortoises with $H$. parvula were located in winter and spring in KZN, and only one individual, an S. pardalis, had both H. fitzsimonsi and H. parvula.

A significantly higher prevalence of 35\% (13/37) of infection with $H$. fitzsimonsi occurred in captive $S$. par- dalis at the NZG, compared with that of 5\% (2/41) in the wild-caught specimens of this tortoise $(p=0.0002)$. However, no significant difference $(p=0.04)$ in parasitaemia occurred between captive $(\sim 5.1 \%)$ and wild-caught specimens of this tortoise $(2.5 \%)$. Female $S$. pardalis from the NZG showed a significantly greater prevalence of infection $(43.5 \%, 10 / 23)$ than males $(21.4 \%, 3 / 14)(p=0.002)$, and a negative correlation $\left(\mathrm{r}^{2}=<1.00\right)$ between increasing weight $(\mathrm{kg})$ of $S$. pardalis and parasitaemia with $H$. fitzsimonsi, detected at the NZG, was not significant statistically $(\mathrm{p}=0.095)$.

Difficulty was experienced in determining numbers of tortoises, wild and captive, infested with ticks, and numbers of ticks per tortoise, as these arthropods tended to reside in deep host skin folds and were not readily detected. However, a few specimens collected from $K$. $b$. belliana, $K$. lobatsiana and $S$. pardalis, were identified as the common African tortoise tick, Amblyomma marmoreum Koch, 1844 while the tick species parasitizing $C$. angulata was Amblyomma sylvaticum (De Geer, 1778) (see Fielden and Rechav 1994). Thus, 7 specimens of $A$. marmoreum were removed from a wild $S$. pardalis and a wild $K$. lobatsiana, both from NWP, and from a captive $K$. b. belliana from KZN, while 7 specimens of $A$. sylvaticum were taken from a wild $C$. angulata from WC.

\section{Haemogregarina (sensu lato) fitzsimonsi Dias, 1953 Developmental stages within the blood of tortoises}

Trophozoites: occurring singly within immature erythrocytes (Fig. 2), $3.7 \pm 0.4 \mu \mathrm{m}(3-4.3 \mu \mathrm{m})$ long by $1.0 \pm 0.1 \mu \mathrm{m}(0.8-1.1 \mu \mathrm{m})$ wide $(\mathrm{n}=10)$, curved with rounded or bluntly pointed ends, finely vacuolated cytoplasm stained whitish-blue, nucleus $1.7 \pm 0.1 \mu \mathrm{m}$ $(1.5-1.8)$ by $0.9 \pm 0.2 \mu \mathrm{m}(0.6-1.2 \mu \mathrm{m})(\mathrm{n}=10)$ centrally placed, or closer to one pole than the other, loosely arranged chromatin, stained pink or purple.

Table 1. Host species, host status ( $\mathrm{W}=$ wild, $\mathrm{C}=$ captive), and seasons $(\mathrm{Sp}=$ spring, $\mathrm{Su}=$ summer, $\mathrm{A}=$ autumn, $\mathrm{W}=$ winter $)$ in which tortoises were examined. Location of captured individuals, including Gauteng (G), Kwazulu-Natal (KZN), North West Province (NWP) and Western Cape (WC), parasite prevalence (\%) with H. fitzsimonsi (H. $f)$ and H. parvula (H. $p$ ) and seasons in which parasitized tortoises were found. Total parasite prevalence for individual and all provinces.

\begin{tabular}{|c|c|c|c|c|c|c|c|c|c|c|}
\hline \multirow[t]{3}{*}{ Host tortoises } & \multirow{3}{*}{$\begin{array}{l}\text { Status }(\mathrm{n}) / \text { Seasons } \\
\text { tortoises were } \\
\text { examined }\end{array}$} & \multicolumn{8}{|c|}{$\begin{array}{c}\text { Hosts parasitized/ } \\
\text { Province (Prevalence, \%)/ } \\
\text { Seasons in which infections were recorded }\end{array}$} & \multirow{3}{*}{$\begin{array}{l}\text { Hosts parasitized } \\
\text { All provinces } \\
\text { (Prevalence, \%) }\end{array}$} \\
\hline & & \multicolumn{2}{|l|}{ G } & \multicolumn{2}{|l|}{$\mathrm{KZN}$} & \multicolumn{2}{|l|}{ NWP } & \multicolumn{2}{|l|}{ WC } & \\
\hline & & H.f & H. $p$ & $H . f$ & H. $p$ & $H . f$ & H. $p$ & $H . f$ & H. $p$ & \\
\hline \multirow[t]{2}{*}{ Chersina angulata } & $\mathrm{W}(16) / \mathrm{Su}$ & & & & & & & $6 / 16(38) \mathrm{Su}$ & $0 / 16(0)$ & $6 / 16(38)$ \\
\hline & $\mathrm{C}(4) / \mathrm{Sp}, \mathrm{Su}$ & $0 / 1(0)$ & $0 / 1(0)$ & $0 / 3(0)$ & $0 / 3(0)$ & & & & & $0 / 4(0)$ \\
\hline $\begin{array}{l}\text { Kinixys belliana } \\
\text { belliana }\end{array}$ & $\mathrm{C}(14) / \mathrm{Sp}, \mathrm{Su}, \mathrm{W}$ & & & 6/14 (48) Sp & 2/14 (14) Sp & & & & & $8 / 14(57)$ \\
\hline \multirow[t]{2}{*}{ Kinixys lobatsiana } & $\mathrm{W}(27) / \mathrm{A}, \mathrm{W}$ & & & & & $2 / 27(7) \mathrm{A}$ & $0 / 27(0)$ & & & $2 / 27(7)$ \\
\hline & $\mathrm{C}(2) / \mathrm{Su}$ & $1 / 2(50) \mathrm{Su}$ & $0 / 2(0)$ & & & & & & & $1 / 2(50)$ \\
\hline Kinixys natalensis & $\mathrm{C}(3) / \mathrm{Sp}, \mathrm{W}$ & & & $2 / 3(66) \mathrm{Sp}$ & $0 / 3(0)$ & & & & & $2 / 3(66)$ \\
\hline \multirow[t]{2}{*}{ Stigmochelys pardalis } & W (41)/Sp, Su, W & & & & & $2 / 41(5) \mathrm{Su}$ & $0 / 41(0)$ & & & $2 / 41(5)$ \\
\hline & $\mathrm{C}(47) / \mathrm{Sp}, \mathrm{Su}, \mathrm{W}$ & $13 / 37(35) \mathrm{Sp}$ & $0 / 37(0)$ & $3 / 10(30) \mathrm{W}$ & $1 / 10(10) \mathrm{W}$ & & & & & $17 / 47(36)$ \\
\hline Total/Province $(\%)$ & C \& W (154) & $14 / 40(35)$ & $0 / 40(0)$ & $11 / 30$ & $3 / 30(10)$ & $4 / 68(6)$ & $0 / 68(0)$ & $6 / 16(38)$ & $0 / 16(0)$ & \\
\hline Total $(\%)$ & & & & & & & & & & $38 / 154(25)$ \\
\hline
\end{tabular}


Binucleate meronts, or closely apposed paired individuals: curved with rounded or bluntly pointed ends (Figs. $3,4), 4.0 \pm 0.2 \mu \mathrm{m}(3.6-4.3 \mu \mathrm{m})$ long by $1.9 \pm 0.4 \mu \mathrm{m}$ $(1.3-2.6 \mu \mathrm{m})$ wide $(\mathrm{n}=10)$, cytoplasm vacuolated, stained whitish-blue, paired nuclei with loose chromatin, $1.2 \pm 0.1 \mu \mathrm{m}(1.1-1.3 \mu \mathrm{m})$ long by $0.5 \pm 0.1 \mu \mathrm{m}(0.5$ $0.6 \mu \mathrm{m})$ wide $(\mathrm{n}=5)$, stained pinkish-purple, often lying centrally within parasite body; these stages occasionally associated with single individuals (trophozoites or merozoites) within a single immature erythrocyte (Fig. 4).

Merozoites: likely the result of meront division, lying in pairs within immature erythrocytes, each $3.8 \pm 0.3 \mu \mathrm{m}$ $(3.4-4.3 \mu \mathrm{m})$ long by $1.3 \pm 0.1 \mu \mathrm{m}(1.1-1.5 \mu \mathrm{m})$ wide $(\mathrm{n}=10)$; cytoplasm much less vacuolated than in trophozoites and meronts, stained whitish-blue (Fig. 5); nucleus similar to that of trophozoite, centrally placed, or closer to one pole than the other, stained pink, $1.6 \pm 0.2 \mu \mathrm{m}(1.3$ $1.9 \mu \mathrm{m})$ long by $1.0 \pm 0.1 \mu \mathrm{m}(0.9-1.1 \mu \mathrm{m})(\mathrm{n}=10)$. No parasitophorous vacuole evident surrounding merozoites, trophozoites or meronts.

Immature gamonts: lying singly (Fig. 6), or frequently in adjacent (Figs. 7, 8) or opposing (Fig. 9) pairs in parasitophorous vacuoles, within mature erythrocyte cytoplasm, or extracellular (Fig. 10); slender and elongate, or curled (Figs. 8, 9), $17.8 \pm 1.2 \mu \mathrm{m}(14.3-19.6 \mu \mathrm{m})$ long by $2.3 \pm 0.4 \mu \mathrm{m}(1.6-3.0 \mu \mathrm{m})$ wide $(\mathrm{n}=12)$; whitish-blue staining cytoplasm without vacuolation; rectangular or oval nucleus, chromatin more condensed than in previous stages, stained purple, usually nearer one pole of individual than the other, $2.0 \pm 0.4 \mu \mathrm{m}(1.4-2.8 \mu \mathrm{m})$ long by $0.9 \pm 0.1 \mu \mathrm{m}(0.7-1.0 \mu \mathrm{m})$ wide $(\mathrm{n}=10)$.

Mature gamonts: lying singly (Figs. 11, 12), or occasionally in pairs (Fig. 13) within mature erythrocytes (Figs. 11-13), $17.5 \pm 0.3 \mu \mathrm{m}(17.1-17.7 \mu \mathrm{m})$ long by $3.9 \pm 0.5 \mu \mathrm{m}(3.3-4.3 \mu \mathrm{m})(\mathrm{n}=36)$, also extracellular (Fig. 14); elongate, curved, sometimes with one broad pole and opposite, a small recurved tail; whitish-blue stained cytoplasm without vacuoles or granules; pink or purple stained nucleus, square or oval, $4.8 \pm 0.3 \mu \mathrm{m}(4.5-$ $5 \mu \mathrm{m})$ long by $2.9 \pm 0.4 \mu \mathrm{m}(2.4-3.2 \mu \mathrm{m})(\mathrm{n}=36)$, lying nearer one pole (anterior ?) than the other; parasitophorous vacuole (or thin capsule ?) of intracellular gamont narrower than in immature stages, appearing to persist in extracellular form (Fig. 14). Host cell nuclei compressed and displaced by meront and gamont stages.

Vertebrate type host: Kinixys belliana belliana(Gray). Vertebrate hosts from this study: Chersina angulata (Schweigger), Kinixys belliana belliana (Gray), K. lobatsiana Power, K. natalensis Hewitt and Stigmochelys pardalis (Bell) (Testudinidae, Cryptodira).

Type locality: Maputo, Mozambique.

Localities in this study: Gauteng (National Zoological Gardens); Kwazulu-Natal (Crocodile Creek, Crocodile Valley, Flag Animal Farm), Ballito; North West (Rustenburg, rural markets); Western Cape (Hondeklip Bay, Velddrif).
Site of infection: Peripheral blood.

Vector: Unknown.

Deposition of voucher specimens: Protozoan collection of the South African Museum, Cape Town, South Africa (blood film of $C$. angulata with mature gamonts, SAM A25092; blood film of $K . b$. belliana with mature gamonts, SAM A25093; blood film of $K$. lobatsiana with mature gamonts, SAM A25094; blood film of $K$. natalensis with mature gamonts, SAM A25095; blood film of $S$. pardalis with trophozoites, probable meronts, merozoites, immature gamonts and mature gamonts, SAM A25096).

Remarks. The gamont stages of $H$. fitzsimonsi described by Dias (1953) were long, slender and curved, with one end broader than the other, and they measured $15.84-18.81 \mu \mathrm{m}$ long by $3.63-5.61 \mu \mathrm{m}$ wide. Their cytoplasm was homogeneous, while nuclei were square in outline, often placed excentrically within the parasite body and sometimes condensed; each nucleus was $7.5 \mu \mathrm{m}$ long by $4.62 \mu \mathrm{m}$ wide. The surface membrane of the gamont formed a halo, slightly brighter than the parasite cytoplasm. In the current study, the mature gamont stages of the haemogregarine parasitizing five species of tortoises, from four provinces sampled in South Africa, appeared identical to those of $H$. fitzsimonsi in general appearance, comparable in size, and similar in having a prominent parasitophorous vacuole. The mature gamont form from South African tortoises is thus identified as a development stage of $H$. fitzsimonsi.

Haemogregarina bruneti, which Commes (1919) reported from K. homeana captured near Bamako, Mali, has gamonts of greater width $(7 \mu \mathrm{m})$, but similar length $(16.8 \mu \mathrm{m})$, to those of $H$. fitzsimonsi, with these gamonts possibly contained within a thin capsule. The gamont nucleus of $H$. bruneti is irregular, gamont cytoplasm is reticulated with $\sim 20$ characteristic granules, and the shape and volume of the host erythrocyte is altered markedly by the parasite presence. Dias (1953) concluded that this was a different species from H. fitzsimonsi and we concur with his opinion.

Dias (1953) also described briefly, a dumb-bell like form of H. fitzsimonsi, absent from the present material. However, we detected haemogregarine stages which Dias (1953) did not report, namely trophozoites, and probable meronts, merozoites and immature gamonts. These forms occurred alongside what are interpreted here as the mature gamonts of Dias' haemogregarine in two wild-caught $C$. angulata from Velddrif and three $S$. pardalis from the $\mathrm{NZG}$, and therefore they are provisionally identified as developmental stages of H. fitzsimonsi.

Dias (1953) collected his two parasitized tortoises in Maputo, Mozambique, but in the current study tortoises from four South African provinces were infected, indicating that $H$. fitzsimonsi is not host-specific among land tortoises from southern Africa, and has a broad geographical range. 


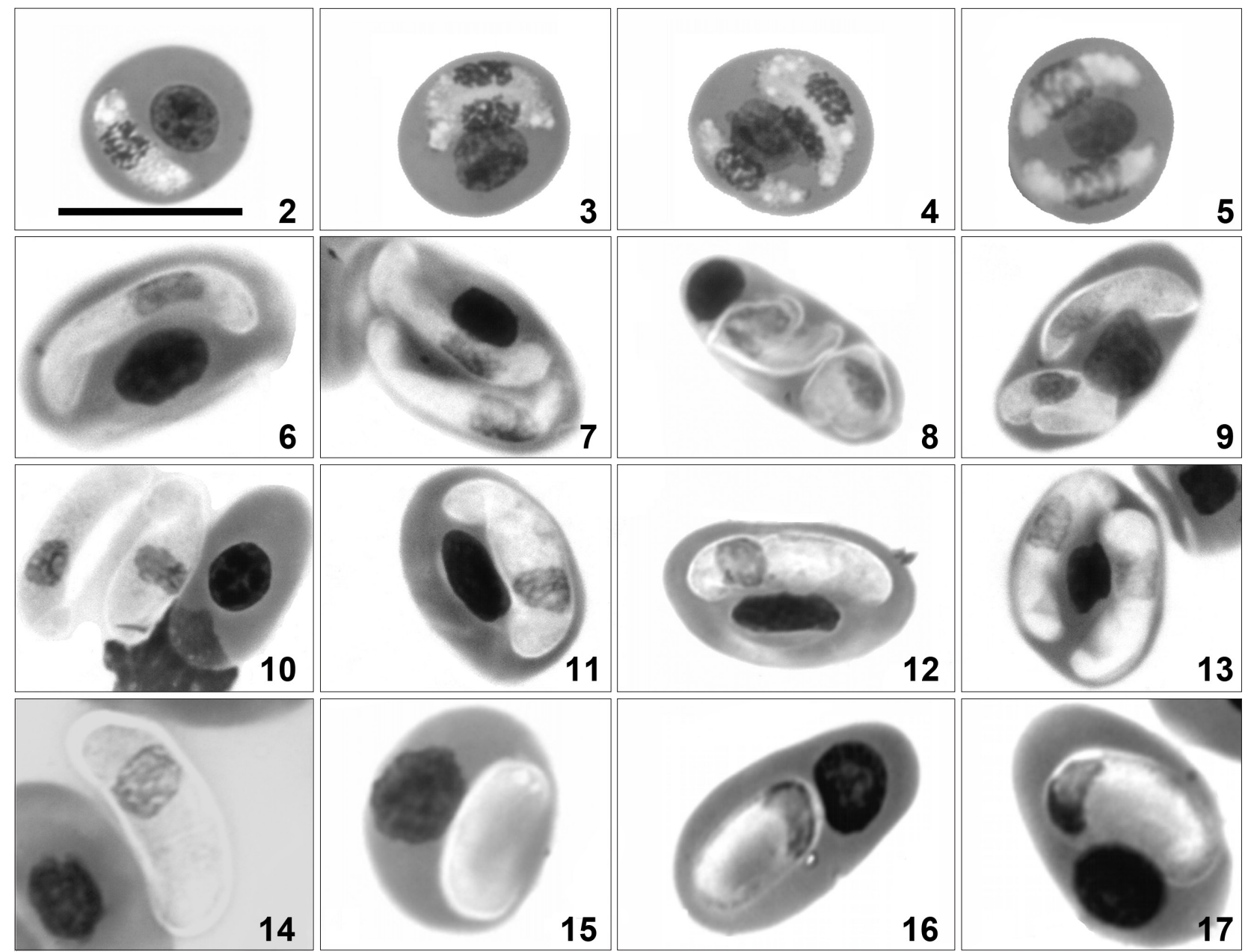

Figs. 2-17. Giemsa-stained blood films of Stigmochelys pardalis with Haemogregarina fitzsimonsi (Figs. 2-14) and Haemogregarina parvula (Figs. 15-17) infecting immature (Figs. 2-5, 15) and mature erythrocytes (Figs. 6-14, 16, 17). Fig. 2. Trophozoite. Figs. 3, 4. Meronts in division, or closely opposed individuals. Fig. 5. Paired merozoites. Figs. 6-10. Immature gamonts singly, or in pairs, within erythrocytes, or extracellularly. Figs. 11-13. Mature gamonts singly or in pairs within erythrocytes. Fig. 14. Extracellular mature gamont. Fig. 15. Immature encapsulated gamont. Figs. 16, 17. Mature encapsulated gamonts. Scale bar (Figs. 2-17) $=10 \mu \mathrm{m}$.

\section{Haemogregarina (sensu lato) parvula Dias, 1953}

\section{Developmental stages within the blood of tortoises}

Two stages, probably immature and mature intraerythrocytic gamonts (Figs. 15-17) of H. parvula were observed in two captive specimens of $K$. b. belliana, and one captive $S$. pardalis, both in KZN. The $S$. pardalis was also parasitized by H. fitzsimonsi, but this haemogregarine was not observed in the blood of the two infected $K . b$. belliana.

Immature and mature gamonts of $H$. parvula were broadly oval, with ill-defined perimeters, and enclosed by a non-staining capsule. Only two immature gamonts were observed, but their overall outline was similar in size to that of mature gamonts, measuring 10.9 and $12.1 \mu \mathrm{m}$ long, by 5 and $6.4 \mu \mathrm{m}$ wide $(\mathrm{n}=2)$. The nucleus of this younger stage was not visible and the parasite cytoplasm, which was difficult to discern, appeared to stain pale blue, and lack granules or vacuoles (Fig. 15). This stage was observed in immature erythrocytes, where host nuclei were displaced.

Mature gamonts of $H$. parvula occurred in mature erythrocytes, also inducing host nucleus displacement. Overall measurements of mature gamonts in $K$. $b$. belliana, were $11.3 \pm 0.4 \mu \mathrm{m}(11-12.1 \mu \mathrm{m})$ long by $6.2 \pm 0.6 \mu \mathrm{m}(5.4-7.2 \mu \mathrm{m})$ wide $(\mathrm{n}=6)$, with nuclei measuring $3.2 \pm 0.9 \mu \mathrm{m}(2.4-4.9 \mu \mathrm{m})$ long by $4.4 \pm 0.4 \mu \mathrm{m}$ $(4-5.1 \mu \mathrm{m})$ wide $(\mathrm{n}=6)$. Mature gamonts (Figs. 16,17$)$ in $S$. pardalis measured $11.5 \pm 0.4 \mu \mathrm{m}(11-12 \mu \mathrm{m})$ long by $6 \pm 0.3 \mu \mathrm{m}(5.4-6.1 \mu \mathrm{m})$ wide $(\mathrm{n}=5)$, with nuclei measuring $3.2 \pm 0.9 \mu \mathrm{m}(2.2-4 \mu \mathrm{m})$ long by $4.4 \pm 0.3 \mu \mathrm{m}$ $(4-4.6 \mu \mathrm{m})$ wide $(\mathrm{n}=5)$. The nucleus of mature gamonts (Figs. 16, 17), stained deep purple and lay terminally, suggesting that the gamont body may be bent double within the capsule. Cytoplasm stained pale blue and lacked granules, or vacuolation. Extracellular gamonts were not seen. 
Vertebrate type host: Kinixys belliana belliana(Gray).

Vertebrate hosts from this study: Kinixys belliana belliana (Gray), Stigmochelys pardalis (Bell) (Testudinidae, Cryptodira).

Type locality: Maputo, Mozambique.

Localities in this study: Kwazulu-Natal (Crocodile Creek, Flag Animal Farm), Ballito.

Site of infection: Peripheral blood.

Vector: Unknown.

Deposition of voucher specimens: Protozoan collection of the South African Museum, Cape Town, South Africa (blood film of $K$. b. belliana with immature and mature intraerythrocytic gamonts, SAM A25097; blood film of $S$. pardalis with mature intraerythrocytic gamonts, SAM A25098).

Remarks. The gamont stages observed in $K$. b. belliana and S. pardalis resemble Dias' (1953) description of encapsulated $H$. parvula very closely, and as in the current study, he reported low parasitaemias. Dias' gamonts were 9.2-13.2 $\mu \mathrm{m}$ long by 5.67-5.94 $\mu \mathrm{m}$ wide, and were thus slightly longer, but of similar width to those recorded in this study. The parasite nucleus also occurred at one pole, in both the mature gamont of this and Dias' parasite, while the immature gamont exhibited no stained nucleus. Furthermore, host erythrocyte nuclei were greatly displaced in both the current and Dias' material. The similarities between Dias' H. parvula and the haemogregarine reported here draw us to the conclusion that they are identical. Thus, the host and geographical ranges of $H$. parvula have been extended within KZN.

Northern KZN (the source of H. parvula in this study) shares a subtropical climate and general habitat type with Maputo, Mozambique from which Dias (1953) obtained his parasitized tortoises. This suggests that, unlike $H$. fitzsimonsi, H. parvula may be a habitat-specific haemogregarine. However, the encapsulated blood gamonts of H. parvula are also close in size and appearance to those of Hemolivia mauritanica from the spur-thighed tortoise, Testudo graeca, from Algeria (12-15 by $6 \mu \mathrm{m}$ ) (see Sergent and Sergent 1904), and from the same tortoise host from Bulgaria and Turkey, and the marginated tortoise Testudo marginata Schoepff from Greece (both, 10-14 by 4-7 $\mu \mathrm{m}$ ) (Široký et al. 2005). The possibility that $H$. parvula is a member of the genus Hemolivia, or may be $H$. mauritanica itself, is discussed further below.

\section{DISCUSSION}

Among them, five South African tortoise species appear to contain the haemogregarine species, Haemogregarina fitzsimonsi and Haemogregarina parvula, recorded by Dias (1953) from Maputo, Mozambique. Siddall (1995) regarded $H$. parvula as a synonym of $H$. fitzsimonsi, with the latter taking priority. However, in the current study, both parasites were detected in only one tortoise, a captive Stigmochelys pardalis in Kwazulu-Natal (KZN), and thus we prefer, at present, to retain their status as separate species of haemogregarines.

Haemogregarina parvula was observed in a new host (S. pardalis) and in a new locality (Ballito) within KZN, but no stages of development, other than those noted by Dias were observed. On the other hand, the distribution and host range of $H$. fitzsimonsi were much greater than for $H$. parvula, and additional blood stages were located, with probable meronts, paired merozoites and paired immature gamonts pointing to the existence of intraerythrocytic division. Superficially, this would support the classification of $H$. fitzsimonsi as a member of the genus Haemogregarina sensu stricto (see Siddall 1995). However, it is difficult to accept that South African savannah and arid-land tortoises (from Gauteng, North West Province, and the Western Cape) are infested with leeches, supposedly the vectors of chelonian Haemogregarina spp. (see Siddall 1995), even if tortoises in KZN encounter moist conditions. These observations, coupled with the existence of ticks of two species, Amblyomma marmoreum and A. sylvaticum, found parasitizing some host animals, suggest that $H$. fitzsimonsi may not be a Haemogregarina sp., but a species of Hemolivia, or of Hepatozoon Miller, 1908, both of which use ticks as definitive hosts (see Davies and Johnston 2000).

Haemogregarina parvula may also be a haemogregarine of this type, since it clearly has encapsulated stages in host erythrocytes, a feature of Hemolivia species (see Široký et al. 2007). The similarity in morphology and size between the encapsulated forms of H. parvula and Hemolivia mauritanica from Testudo graeca and T. marginata is striking (see above). However, whether H. mauritanica can exist outside the vertebrate host genus Testudo is unclear at present, and the parasite may not be conspecific with $H$. parvula from Kinixys belliana belliana and $S$. pardalis. Furthermore, proving that $H$. fitzsimonsi and $H$. parvula are members of a genus such as Hemolivia, rather than Haemogregarina, will require detailed cycle studies like those of Michel (1973), Landau and Paperna (1997) and recently, Široký et al. (2004, 2005, 2007). To date, $H$. mauritanica is the only species of the genus Hemolivia recorded from land tortoises and a tick vector, Hyalomma aegyptium L. (see Široký et al. 2007). In his study, Dias (1953) reported the tick Amblyomma nuttalli Dönitz, 1909 to parasitize $K$. b. belliana. However, this tick species was not found in the present study.

Haemogregarina fitzsimonsi can be detected in all seasons in South African tortoises. As judged by host weight, it also exists in younger and older $S$. pardalis housed at the National Zoological Gardens (NZG), Pretoria. Comparison of data from wild and captive specimens showed that prevalence of $H$. fitzsimonsi infections in this tortoise is significantly greater in captive hosts, but not parasitaemia. Furthermore, female $S$. pardalis at the NZG showed a significantly higher prevalence of infection with $H$. fitzsimonsi than males. In the wild, female tortoises roam 
widely through male territories (Branch 1998, 2008), possibly increasing their vector contact as they move from one territory to another. However, although greater tick intensities in captive situations may increase the likelihood of haemogregarine transmission, we have no evidence of this at the NZG, and a gender difference in prevalence is difficult to explain at present. In contrast to our observations, Široký et al. (2005) detected no substantial difference in prevalence of $H$. mauritanica among female, male and juvenile T. marginata from Greece. However, potential host gender influences on prevalence have been observed recently with haematozoan infections in wildcaught fish from Brazil (Davies et al. 2008).

Acknowledgements. We are most grateful to Prof. Jorge Eiras, University of Oporto, Portugal, for obtaining the work of Dias (1953) for us and translating it from Portuguese. We would also like to thank the National Zoological Gardens, Crocodile Creek, Crocodile Valley and Flag Animal Farm for allowing us to examine their tortoises. This work has been funded by a University of Johannesburg Sasol Fund Research Grant.

\section{REFERENCES}

Bouet J. 1909: Sur deux hémocytozaires pigmentés des reptiles. C. R. Soc. Seances Soc. Biol. 66: 43-45.

Branch B. 1998: Field Guide to Snakes and Other Reptiles of Southern Africa. Struik Publishers, Cape Town, 399 pp.

BRANCh B. 2008: Tortoises, Terrapins and Turtles of Africa. Struik Publishers, Cape Town, 128 pp.

Commes C. 1919: Hémogrégarine et trypanosome d'un chelonian (Cinixis homeana). Bull. Soc. Pathol. Exot. 12: 14-16.

Davies A.J., Amado L.L., Cook R.T., Bianchini A., Eiras J.C. 2008: Potential environmental and host gender influences on prevalence of Haemogregarina platessae (Adeleorina: Haemogregarinidae) and suspected Haemohormidium terraenovae (incertae sedis) in Brazilian flounder from the Patos Lagoon Estuary, Southern Brazil. Folia Parasitol. 55: 161-170.

Davies A.J., Johnston M.R.L. 2000: The biology of some intraerythrocytic parasites of fishes, amphibians and reptiles. Adv. Parasitol. 45: 1-107.

Dias J.A.T.S. 1953: Subsídios para o estudo dos hematozoários dos répteis de Moçambique. Moçamb. Bol. Soc. Estud. 23: 41-73.

Fielden L.J., Rechav Y. 1994: Attachment sites of the tick Amblyomma marmoreum on its tortoise host, Geochelone pardalis. Exp. Appl. Acarol. 18: 339-349.

Lainson R., Naiff R.D. 1998: Haemoproteus (Apicomplexa: Haemoproteidae) of tortoises and turtles. Proc. R. Soc., Lond. 265: 941-949.

Landau I., Paperna I. 1997: The assignment of Hepatozoon mauritanicum, a tick-transmitted parasite of tortoise, to the genus Hemolivia. Parasite 4: 365-367.

LaVeran M.A. 1905: Sur une hémamibe nouvelle de Testudo pardalis. C. R. Soc. Seances Soc. Biol. 59: 176-178.
McArthur S., Wilkinson R., Meyer J. 2004: Medicine and Surgery of Tortoises and Turtles. Blackwell Publishing, Oxford, 579 $\mathrm{pp}$.

Michel J.C. 1973: Hepatozoon mauritanicum (Et. et Ed. Sergent, 1904) n. comb., parasite de Testudo graeca: redescription de la sporogonie chez Hyalomma aegyptium et de la schizogonie tissulaire d'apres le materiel d'E. Brumpt. Ann. Parasitol. Hum. Comp. 48: 11-21.

Plimmer H.G. 1912: On the blood parasites found in animals in the Zoological Gardens during the four years 1908-1911. Proc. Zool. Soc. Lond. 27: 406-419.

SidDAll M.E. 1995: Phylogeny of adeleid blood parasites with a partial systematic revision of the haemogregarine complex. J. Eukaryot. Microbiol. 42: 116-125.

Sergent E., Sergent E. 1904: Sur une hémogrégarine, parasite de Testudo mauritanica. C. R. Soc. Biol. 56: 130-131.

Šroký P., Kamler M., Frye F.L., Fictum P., Modrý D. 2007: Endogenous development of Hemolivia mauritanica (Apicomplexa: Adeleina: Haemogregarinidae) in the marginated tortoise Testudo marginata (Reptilia: Testudinidae): evidence from experimental infection. Folia Parasitol. 54: 13-18.

Šr IROKÝ P., KAMLER M., ModrÝ D. 2004: Long-term occurrence of Hemolivia cf. mauritanica (Apicomplexa: Adeleina: Haemogregarinidae) in captive Testudo marginata (Reptilia: Testudinidae): evidence for cyclic merogony? J. Parasitol. 90: 1391-1393.

Široký P., Kamler M., ModrÝ D. 2005: Prevalence of Hemolivia mauritanica (Apicomplexa: Adeleina: Haemogregarinidae) in natural populations of tortoises of the genus Testudo in the east Mediterranean region. Folia Parasitol. 52: 359-361.

Vetter H. 2002: Terralog: Turtles of the World. Vol. 1: Africa, Europe and West Asia. Edition Chimaira, Frankfurt, 96 pp. 